\title{
A Mathematical Approach to Supply Complexity Management Efficiency Evaluation for Supply Chain
}

\author{
Changhee $\mathrm{Kim}^{1}$ and Soo Wook Kim ${ }^{2}$ \\ ${ }^{1}$ Operations Management, College of Business Administration, Seoul National University, SK Business Center, \\ Room No. 515, Building 58, Gwanakro 1, Gwanakgu, Seoul 151-742, Republic of Korea \\ ${ }^{2}$ Operations Management, College of Business Administration, Seoul National University, SK Business Center, \\ Room No. 501, Building 58, Gwanakro 1, Gwanakgu, Seoul 151-742, Republic of Korea \\ Correspondence should be addressed to Soo Wook Kim; kimsoo2@snu.ac.kr
}

Received 15 October 2015; Accepted 11 November 2015

Academic Editor: Young Hae Lee

Copyright (C) 2015 C. Kim and S. W. Kim. This is an open access article distributed under the Creative Commons Attribution License, which permits unrestricted use, distribution, and reproduction in any medium, provided the original work is properly cited.

\begin{abstract}
This study aims to identify the factors of complexity due to the globalization of supply chain and to measure the management efficiency of the factors which cause the supply complexity within supply chain. This study conducts an analysis to utilize linear programming and bootstrapping, targeting 12 Korean companies among the selected companies in Fortune Global 500. According to the results from the analysis, 4 companies with relatively high management efficiency of the factors which cause the supply complexity and 8 companies with relatively low management efficiency are found. The research findings reveal that public companies with the small number of products, factories, and providers relatively manage the supply complexity compared to private companies. Moreover, this study suggests projection point as a direction for relatively less efficient companies and excess quantity of input which should reduce for its achievement. This study also has an implication to establish a further standard of efficiency to manage the supply complexity for companies.
\end{abstract}

\section{Introduction}

It is not too much to say that this is the age of uncertainty. Due to the development of information communication technology, companies' fields of activities are expanded to the whole world, which leads to the globalization of supply chain. Many Korean companies have expanded their supply chains by establishing foreign factories and taking foreign companies as the 21th century dawns. Although such globalization of supply chain gives positive influences on companies' profits, it also increases uncertainty. Trkman and McCormack [1] indicate uncertainty as a risk factor of supply chain, and Hur et al. [2] make mention of complexity as a determinant factor of supply chain structure. As the globalization of supply chain leads to more customers, the number of services or goods that companies should provide also increases because of a variety of needs of growing customers. In addition, establishing foreign branches or factories also causes complexity such as localization, and making relationships among many companies for global supply chain causes complexity as well.

This study attempts to suggest a standard for the efficient management of growing complexity within supply chain. For this purpose, this study conducts an analysis through linear programming and input-oriented CCR model as a DEA (Data Envelopment Analysis) method utilizing bootstrapping, adopting 12 Korean companies among Fortune Global 500 companies as research targets. In doing so, this study identifies the companies that manage the supply complexity efficiently/inefficiently within supply chain in a relative sense. This study also analyzes projection point which plays the role of a guideline for becoming a target company of benchmarking for the companies that manage the supply complexity inefficiently within supply chain and excess quantity of input which should reduce for the achievement of the efficiency. 


\section{Literature Review}

2.1. Supply Chain Management. Supply Chain Management refers to a concept to manage the flows of products, capital, and information from providers to final customers and recognize them as a chain in a comprehensive perspective $[3,4]$. According to Stevens [5], a range of supply chain starts from supply source. Lee and Billington [6] conceptualize supply chain as a network of all activities. The definition of supply chain by Fine [7] is an activity to integrate capabilities in order to acquire a series of competitive advantages. Tan et al. [8] define supply chain management as a management exceeding general materials/provision management. Ross [9] regards supply chain management as a management philosophy for managing and developing channels continuously. Handfield and Nichols [10] state that the management of these channels can lead to constant competitive advantage. Supply chain management develops to lean operations that aim at the efficient management through the reduction of unnecessary costs by executing the process, such as activities to forecast demands or to balance between supply and demand [11]. However, an uncertain phenomenon to cast difficulties in controlling or managing each chain constructing supply chain appears, which is called supply chain risk.

2.2. Complexity of Supply Chain. A lot of scholars recently indicate uncertainty as a risk factor of supply chain $[1,12-$ 18]. Regarding such uncertainty in supply chain, Hur et al. [2] make mention of the complexity of products as a determinant factor of supply chain structure, and Kim and Ham [19] mention that the types of products, the number of distribution centers and plants, and the types of transportation vehicles are the factors to increase complexity. Bozarth et al. [20] explain the effects of the complexity of supply chain on the performance of manufacturing factories, pointing out the number of products, the number of providers, the number of components, the variability of demands, the number of customers, and the foreign distribution of providers as factors causing the complexity of supply chain. Ashkenas [21] indicates that the number of products, the number of processes, and the number of provider classes cause complexity. Mariotti [22] develops complexity index in his book "Complexity Crisis," mentioning that the number of branches, the number of providers, the number of customers, the number of products, and the function of products are related to complexity. Finally, Wilson and Perumal [23] explain that the number of customers, the cycle of product spans, the number of products, and lead time raise complexity to increase prime costs.

\section{Materials and Methods}

This study follows the research trend presented in Figure 1. First of all, this study conducts literature review on supply chain and the factors causing the supply complexity of supply chain, which leads to the definition of input factor and output factor. Afterwards, this study selects the manufacturing companies to be evaluated on a basis of complexity management efficiency and collects data. It also conducts the DEA method

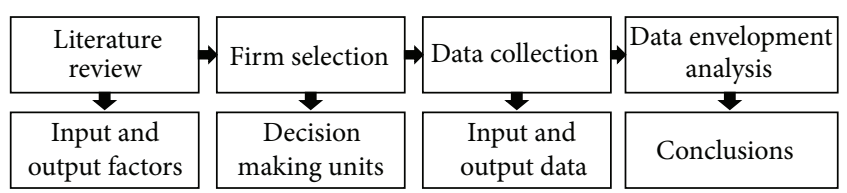

FIgURE 1: Research flow.

to measure the efficiency of supply chain complexity of the manufacturing companies to deduce results.

3.1. Linear Programming and Data Envelopment Analysis. Linear programming is a mathematical technique to optimize the distribution of limited resource to achieve a decision making goal. It mainly covers the issues of maximizing profits or minimizing costs, and all of object functions and constraint conditions are provided in a linear form [24]. DEA to utilize the linear programing above has been widely applied to various fields later. Charnes et al. [25] define DEA as a linear programming method to maximize the rate of output weighted aggregation by input weighted aggregation under the restricted conditions in which the rate of output weighted aggregation by input weighted aggregation of each DMU (Decision making unit) should not exceed 1 and the weighted value of each input and output exceeds 0 . This paper attempts to deduce the information for the enhancement of the efficiency of supply chain complexity management by identifying the targets of benchmarking and the degree of inefficiency of input and output elements as well as the relative efficiency rank among DMU through the DEA method. The degree of efficiency of input and output elements by rank analysis is generally deduced through the Charnes-CooperRhodes (CCR) model or the Banker-Charnes-Cooper (BCC) model. Banker et al. [26] explain the differences between the CCR model and BCC model regarding the understanding of returns to scale. The input-oriented CCR model that assumes constant return to scale utilized in this study is deduced as follows.

Fractional programming problem is as follows:

$$
\begin{aligned}
\operatorname{Max} & \left.h_{0} \text { (Efficiency of } \mathrm{DMU}_{0}\right)=\frac{\sum_{r=1}^{s} u_{r} y_{r 0}}{\sum_{i=1}^{m} v_{i} x_{i 0}} \\
\text { s.t. } & \frac{\sum_{r=1}^{s} u_{r} y_{r j}}{\sum_{i=1}^{s m} v_{i} x_{i j}} \leq 1, \quad j=1,2,3, \ldots, n \\
& u_{r} \geq \varepsilon>0, \quad r=1,2,3, \ldots, s \\
& v_{i} \geq \varepsilon>0, \quad i=1,2,3, \ldots, m,
\end{aligned}
$$

where $u_{r}$ is the weight assigned to the $r$ th output, $v_{i}$ is the weight assigned to the $i$ th input, $y_{r j}$ is the amount of $r$ th output of $\mathrm{DMU}_{j}, x_{i j}$ is the amount of $i$ th inputs of $\mathrm{DMU}_{j}$, $\varepsilon$ is non-Archimedean number, $n$ is the number of DMUs, $m$ is the number of input variables, and $s$ is the number of output variables.

3.2. Input, Output Factors, and Decision Making Units. This study selects 12 companies including Samsung Electronics, 
TABLE 1: Decision Making Units.

\begin{tabular}{|c|c|c|c|c|}
\hline $\mathrm{DMU}$ & Establishment year & Major type of business & Sales* (2014) & Assets* $^{*}$ (2014) \\
\hline Samsung Electronics & 1969 & Electrical goods & 208,938 & 202,876 \\
\hline SK Holdings & 1962 & Telecom, energy & 106,248 & 84,620 \\
\hline Hyundai Motor & 1967 & Automobile & 84,771 & 133,962 \\
\hline POSCO & 1968 & Iron (steel) & 61,504 & 78,110 \\
\hline LG Electronics & 1958 & Electrical goods & 57,038 & 33,729 \\
\hline KEPCO & 1961 & Power transmission & 54,252 & 148,961 \\
\hline KIA Motor & 1944 & Automobile & 44,730 & 37,346 \\
\hline GS Caltex & 1967 & Oil refining & 38,235 & 17,676 \\
\hline Hanwha & 1952 & Gun powder, sensor & 35,574 & 112,542 \\
\hline KOGAS & 1983 & Natural gas & 35,411 & 42,558 \\
\hline S-Oil & 1976 & Oil refining & 27,122 & 933 \\
\hline Lotte Shopping & 1970 & Department store & 26,687 & 36,462 \\
\hline
\end{tabular}

${ }^{*}$ Unit: million dollar (Source: http://fortune.com/global500/).

SK Holdings, Hyundai Motor, POSCO, LG Electronics, Korea Electric Power (KEPCO), KIA Motor, GS Caltex, Hanwha, Korea Gas (KOGAS), and S-Oil, Lotte Shopping and excluding 5 affiliates (Hyundai Heavy Industries, Hyundai Mobis, Samsung Life Insurance, Samsung C\&T, and LG Display), as DMU among 17 Korean companies from Fortune in the standard of 2014 sales amount. The rank of each company in Fortune Global 500 is the 13th, the 57 th, the 99 th, the 162 th, the 175th, the 193th, the 242th, the 30th, the 329th, the 332th, the 439 th, and the 445 th, respectively. The brief explanation for each companies is presented in Table 1.

According to the fixed DMU, this study sets three factors as input factor, drawing reference from the previous studies summarized in Table 2: the number/kind of goods that scholars claim to cause complexity in common, and the number of customers, the number of providers, and the number of plants that more than 2 scholars explain that they cause complexity. The number of customers is excluded due to the inability to conduct actual counting. This study sets sales as output factor which is commonly utilized.

Nyhan and Martin [27] state that the optimal number of inputs and outputs is restricted by DMU in DEA. Since DEA has the characteristics to increase efficient DMU as the number of inputs and outputs grows, the determination of inefficient DMU becomes difficult. In this sense, Banker et al. [26] and Nunamaker [28] insist that the number of DMUs should be three times higher than the aggregation of the number of inputs and outputs. Boussofiane et al. [29] insist that the number of DMUs should exceed the multiplied value of the number of inputs and the number of outputs. The number of DMUs utilized in this study and the number of inputs and outputs is 3 and 1, respectively. It satisfied the standard of DMU, more than 12 by Banker et al. [26] and Nunamaker [28] and more than 3 by Boussofiane et al. [29].

3.3. Data Collection. The collected input data and output data is presented in Table 4, in accordance with the standard of Table 3. "The number of goods," as an input factor, is collected from the number of major purpose businesses based on KGAAP (Korea Generally Accepted Accounting Principles) in
TABLE 2: Complexity factors of supply chain.

\begin{tabular}{|c|c|c|c|c|c|}
\hline Complexity index & A & B & $\mathrm{C}$ & $\mathrm{D}$ & $\mathrm{E}$ \\
\hline The number/kind of goods & $\mathrm{O}$ & $\mathrm{O}$ & $\mathrm{O}$ & $\mathrm{O}$ & $\mathrm{O}$ \\
\hline The number of plants & $\mathrm{O}$ & & & $\mathrm{O}$ & \\
\hline The number of providers & & $\mathrm{O}$ & & $\mathrm{O}$ & \\
\hline The number of raw materials & & $\mathrm{O}$ & & & \\
\hline The hierarchy of providers & & & $\mathrm{O}$ & & \\
\hline The number of transportations & $\mathrm{O}$ & & & & \\
\hline The number of processes & & & $\mathrm{O}$ & & \\
\hline Product life cycle & & & & & $\mathrm{O}$ \\
\hline Lead time of product/process & & & & & $\mathrm{O}$ \\
\hline The number of customers & & $\mathrm{O}$ & & $\mathrm{O}$ & $\mathrm{O}$ \\
\hline Demand volatility of customers & & $\mathrm{O}$ & & & \\
\hline The number of foreign branches & & $\mathrm{O}$ & & & \\
\hline The function of goods & & & & $\mathrm{O}$ & \\
\hline
\end{tabular}

${ }^{*}$ A: Kim and Ham [19], B: Bozarth et al. [20], C: Ashkenas [21], D: Mariotti [22], and E: Wilson and Perumal [23].

2014. "The number of providers" is collected from the total number of related companies of a company. The number of plants is collected from the number of domestic branches, factories, and distribution centers of a company. The total sales as an output factor is collected from each source.

In the formula in (1) mentioned earlier, the object function is nonlinear and constraint condition is nonconvex. Thus, the question can be solved by fixing the weighted aggregation of input of the object function as 1 and converting each DMU to linear programming question like (2) after transforming the constraint condition formula.

Linear programming problem is as follows:

$$
\begin{aligned}
\operatorname{Max} & h_{0}=u_{1} y_{10}, \\
\text { s.t. } & u_{1} y_{10}-\left(v_{1} x_{10}+v_{2} x_{20}+v_{3} x_{30}\right) \leq 0, \\
& v_{1} x_{10}+v_{2} x_{20}+v_{3} x_{30}=1, \\
& u_{1} \geq \varepsilon, \\
& v_{1}, v_{2}, v_{3} \geq \varepsilon .
\end{aligned}
$$


TABLE 3: Data collection.

\begin{tabular}{lll}
\hline Factors & Explanation & Source \\
\hline The number of goods & The number of purpose businesses & K-GAAP \\
The number of providers & The number of connected companies & 2014 Annual Report \\
The number of plants & The number of plants and branches (domestic) & 2014 Annual Report \\
The total sales & The total sales of year & Fortune Global 500 \\
\hline
\end{tabular}

TABLE 4: Input and output data.

\begin{tabular}{|c|c|c|c|c|}
\hline \multirow{3}{*}{$\mathrm{DMU}$} & \multicolumn{4}{|c|}{ Factors } \\
\hline & \multicolumn{3}{|c|}{ Input data } & \multirow{2}{*}{$\begin{array}{c}\text { Output data } \\
\text { The total sales* }\left(y_{1}\right)\end{array}$} \\
\hline & The number of goods $\left(x_{1}\right)$ & The number of providers $\left(x_{2}\right)$ & The number of plants $\left(x_{3}\right)$ & \\
\hline Samsung Electronics & 29 & 159 & 13 & $\$ 208,938$ \\
\hline SK Holdings & 21 & 211 & 25 & $\$ 106,248$ \\
\hline Hyundai Motor & 31 & 90 & 13 & $\$ 84,771$ \\
\hline POSCO & 10 & 264 & 5 & $\$ 61,504$ \\
\hline LG Electronics & 33 & 100 & 17 & $\$ 57,038$ \\
\hline KEPCO & 7 & 76 & 241 & $\$ 54,252$ \\
\hline KIA Motor & 32 & 25 & 39 & $\$ 44,730$ \\
\hline GS Caltex & 24 & 15 & 50 & $\$ 38,235$ \\
\hline Hanwha & 57 & 224 & 17 & $\$ 35,574$ \\
\hline KOGAS & 6 & 20 & 31 & $\$ 35,411$ \\
\hline S-Oil & 9 & 3 & 11 & $\$ 27,122$ \\
\hline Lotte Shopping & 37 & 61 & 74 & $\$ 26,687$ \\
\hline
\end{tabular}

${ }^{*}$ Unit: million dollar.

Since the constraint condition formula in (2) contains $\leq$, it can be summarized as (3) by introducing slack variables. follows:

Linear programming problem with slack variables is as

$$
\begin{array}{ll}
\operatorname{Max} & h_{0}=\theta, \\
\text { s.t. } & \lambda_{0} x_{10}+s_{1}^{-}=\theta x_{10}, \\
& \lambda_{0} x_{20}+s_{2}^{-}=\theta x_{20}, \\
& \lambda_{0} x_{30}+s_{3}^{-}=\theta x_{30}, \\
& \lambda_{0} y_{10}-s_{1}^{+}=y_{10}, \\
& s_{1}^{-}, s_{2}^{-}, s_{3}^{-} \geq 0 \\
& s_{1}^{+} \geq 0 \\
& \lambda_{0} \geq 0
\end{array}
$$

According to the two-stage solution suggested by Arnold et al. [30], this study finds $\theta^{*}$ value of (3), and it also can find $h_{0}^{*}$ value (Efficiency of DMU $\mathrm{DM}_{0}$ ) by finding $s_{r}^{+*}, s_{r}^{-*}$, the value of slack variables by substituting the $\theta^{*}$ value found in (4) below.

Two-stage solution is as follows:

$$
\begin{array}{cl}
\operatorname{Max} & s_{1}^{+}+\left(s_{1}^{-}+s_{2}^{-}+s_{3}^{-}\right) \\
\text {s.t. } & \lambda_{0} x_{10}+s_{1}^{-}=\theta^{*} x_{10}, \\
& \lambda_{0} x_{20}+s_{2}^{-}=\theta^{*} x_{20},
\end{array}
$$

$$
\begin{aligned}
& \lambda_{0} x_{30}+s_{3}^{-}=\theta^{*} x_{30}, \\
& \lambda_{0} y_{10}-s_{1}^{+}=y_{10}, \\
& s_{1}^{-}, s_{2}^{-}, s_{3}^{-} \geq 0 \\
& s_{1}^{+} \geq 0 \\
& \lambda_{0} \geq 0 .
\end{aligned}
$$

The formula for finding the supply complexity management efficiency within supply chain of each $\mathrm{DMU}_{0}$ by utilizing the data in Table 4 is presented in (5) below.

Equation of complexity management efficiency of $\mathrm{DMU}_{0}$ is as follows:

$$
\begin{array}{ll}
\underset{\theta, \lambda}{\operatorname{Min}} \quad h_{0}= & \theta \\
\text { s.t. } \quad 29 \lambda_{1} & +21 \lambda_{2}+31 \lambda_{3}+10 \lambda_{4}+33 \lambda_{5}+7 \lambda_{6} \\
& +32 \lambda_{7}+24 \lambda_{8}+57 \lambda_{9}+6 \lambda_{10}+9 \lambda_{11} \\
& +37 \lambda_{12}+s_{1}^{-}=\theta^{*} x_{10} \\
159 \lambda_{1}+211 \lambda_{2}+90 \lambda_{3}+264 \lambda_{4}+100 \lambda_{5} \\
+ & 76 \lambda_{6}+25 \lambda_{7}+15 \lambda_{8}+224 \lambda_{9}+20 \lambda_{10} \\
& +3 \lambda_{11}+61 \lambda_{12}+s_{2}^{-}=\theta^{*} \\
x_{20} & 13 \lambda_{1}+25 \lambda_{2}+13 \lambda_{3}+5 \lambda_{4}+17 \lambda_{5}
\end{array}
$$




$$
\begin{aligned}
&+241 \lambda_{6}+39 \lambda_{7}+50 \lambda_{8}+17 \lambda_{9}+31 \lambda_{10} \\
&+11 \lambda_{11}+74 \lambda_{12}+s_{3}^{-}=\theta^{*} x_{30}, \\
& 208,938 \lambda_{1}+106,248 \lambda_{2}+84,771 \lambda_{3} \\
&+61,504 \lambda_{4}+57,038 \lambda_{5}+54,252 \lambda_{6} \\
&+44,730 \lambda_{7}+38,235 \lambda_{8}+35,574 \lambda_{9} \\
& \quad+35,411 \lambda_{10}+27,122 \lambda_{11}+26,687 \lambda_{12}+s_{1}^{+} \\
&=y_{10}, \\
& \lambda_{1}, \lambda_{2}, \lambda_{3}, \lambda_{4}, \lambda_{5}, \lambda_{6}, \lambda_{7}, \lambda_{8}, \lambda_{9}, \lambda_{10}, \lambda_{11}, \lambda_{12} \geq 0 .
\end{aligned}
$$

Afterwards, the procedure to conduct bootstrapping after eliminating the bias of efficiency score according to Simar and Wilson [31] in order to compare the efficiency per each institution has 5 stages, presented below. This study deduces the estimated value of efficiency by repeating the 5-stage procedure 2,000 times.

(1) Calculate the technical efficiency score $\widehat{\emptyset}_{k}(k=1$, $2,3, \ldots, L)$ on individual DMU by finding the score of standard linear programming DEA model.

(2) Generate a random sample in the size $L$ from $\left\{\widehat{\emptyset}_{k}(k=\right.$ $1,2,3, \ldots, L)\}$ to utilize a kernel density estimation to provide $\left\{\emptyset_{1 b}^{*}, \emptyset_{2 b}^{*}, \emptyset_{3 b}^{*}, \ldots, \emptyset_{L b}^{*}\right\}$.

(3) Calculate $\left\{\left(x_{k}, y_{k b}^{*}\right), k=1,2,3, \ldots, L\right\}$ as pseudodata set to generate reference bootstrap technology.

(4) Calculate bootstrap efficiency estimation $\widehat{\emptyset}_{k b}^{*}(k=1$, $2,3, \ldots, L)$ of technical efficiency score of each DMU, $\widehat{\emptyset}_{k}(k=1,2,3, \ldots, L)$, by finding the values of a bootstrap corresponding model.

(5) In order to obtain the bootstrap efficiency estimation $\left\{\widehat{\emptyset}_{k b}^{*}(b=1,2,3, \ldots, B)\right\}$, it is repeatedly calculated $B$ times ( $B$ is a larger number). Hall [32] suggests $B=$ 1,000 to ensure the proper range of the confidence interval, and Simar and Wilson [33] suggest $B=$ 2,000 .

\section{Results and Discussion}

The results of finding the $\theta$ value as the supply complexity management efficiency within supply chain of each company to assume constant return to scale by utilizing the collected data of input and output are presented in Figure 2. Each $\lambda$ value is presented in Table 5. The results on slack variables are presented in Table 6 . The analysis results reveal that the most efficient DMUs are the 4 companies: S-Oil, KOGAS, KEPCO, and Samsung Electronics. Among them, KEPCO and KOGAS are found to manage supply complexity efficiently in spite of their statuses as public companies. The companies that manage supply complexity most inefficiently are Hanwha and Lotte Shopping, of which supply complexity management efficiency within supply chain is less than 0.2. It implies that inefficient DMU can reduce more than $80 \%$ of consumption of input factors without the reduction of sales.
Examining the results of Tables 5 and 6, Samsung Electronics and S-Oil show the highest reference frequency among the 4 companies with the most efficient supply complexity management, while KOGAS and KEPCO have lower reference frequency of 3 and 2, respectively. It can be interpreted that the statuses of KOGAS and KEPCO as public companies have structural differences from other DMUs, as mentioned earlier. Based on the analysis results, the excess quantity of input that should reduce to be reference set with efficiency and the shortage of output that should increase for the cases of the 8 companies with inefficient supply complexity within supply chain can be found through the formula in (6) below.

Excess quantity of inputs and shortage of output:

$$
\begin{aligned}
& \left(\widehat{x_{i 0}}, \widehat{y_{r 0}}\right)=\text { Projection Point of }\left(x_{i 0}, y_{r 0}\right) \\
& \text { (1) Excess Quantity of Input }=x_{i 0}-\widehat{x_{i 0}} \\
& \text { (2) Shortage of Output }=y_{r 0}-\widehat{y_{r 0}} \\
& \widehat{x_{i 0}}=\sum_{j=1}^{n} \lambda_{j}^{*} x_{i j}=\theta^{*} x_{i 0}-s_{i}^{-*}, \quad \forall i \\
& \widehat{y_{r 0}}=\sum_{j=1}^{n} \lambda_{j}^{*} y_{r j}=y_{r 0}-s_{r}^{+*}, \quad \forall i
\end{aligned}
$$

Assuming that output is consistent by utilizing the formula in (6), the excess quantity of input and projection point of each DMU is presented in Table 7. The projection points of the companies with efficient supply complexity management, such as Samsung Electronics, KEPCO, KOGAS, and SOil, are themselves, and the excess quantity of input is 0 . Examining the companies with inefficient supply complexity management, the number of goods that Hanwha and Lotte Shopping cover is too much compared to other companies.

The results from conducting Bootstrap DEA for the comparison of efficiency among industry clusters are presented in Table 8. As a result, the cases of public companies such as KEPCO and KOGAS have the highest complexity management efficiency as 0.7973 and 0.7804 , respectively. In the case of private companies, manufacturing companies have higher complexity management efficiency, for instance, POSCO, Samsung Electronics, and Hyunda Motor. In particular, Lotte Shopping in service industry has the lowest complexity management efficiency, which shows the difficulties in managing the complexity of service industry.

\section{Conclusion}

This study attempts to find a method to evaluate the efficient management of supply complexity within supply chain by utilizing Data Envelopment Analysis based on linear programming. For this purpose, 12 companies including Samsung Electronics, SK Holdings, Hyundai Motor, POSCO, LG Electronics, Korea Electric Power (KEPCO), KIA Motor, GS Caltex, Hanwha, Korea Gas (KOGAS), S-Oil, Lotte Shopping are selected as DMU among 17 Korean companies from Fortune Top 500 companies in the standard of sales amount 
TABLe 5: Data Envelopment Analysis result.

\begin{tabular}{lcccccccccccc}
\hline DMU & $\lambda_{1}$ & $\lambda_{2}$ & $\lambda_{3}$ & $\lambda_{4}$ & $\lambda_{5}$ & $\lambda_{6}$ & $\lambda_{7}$ & $\lambda_{8}$ & $\lambda_{9}$ & $\lambda_{10}$ & $\lambda_{11}$ & $\lambda_{12}$ \\
\hline Samsung Electronics & 1.00 & 0.00 & 0.00 & 0.00 & 0.00 & 0.00 & 0.00 & 0.00 & 0.00 & 0.00 & 0.00 & 0.00 \\
SK Holdings & 0.50 & 0.00 & 0.00 & 0.00 & 0.00 & 0.05 & 0.00 & 0.00 & 0.00 & 0.00 & 0.00 & 0.00 \\
Hyundai Motor & 0.36 & 0.00 & 0.00 & 0.00 & 0.00 & 0.00 & 0.00 & 0.00 & 0.00 & 0.00 & 0.34 & 0.00 \\
POSCO & 0.29 & 0.00 & 0.00 & 0.00 & 0.00 & 0.00 & 0.00 & 0.00 & 0.00 & 0.00 & 0.00 & 0.00 \\
LG Electronics & 0.23 & 0.00 & 0.00 & 0.00 & 0.00 & 0.00 & 0.00 & 0.00 & 0.00 & 0.00 & 0.31 & 0.00 \\
KEPCO & 0.00 & 0.00 & 0.00 & 0.00 & 0.00 & 1.00 & 0.00 & 0.00 & 0.00 & 0.00 & 0.00 & 0.00 \\
KIA Motor & 0.04 & 0.00 & 0.00 & 0.00 & 0.00 & 0.00 & 0.00 & 0.00 & 0.00 & 0.03 & 1.33 & 0.00 \\
GS Caltex & 0.00 & 0.00 & 0.00 & 0.00 & 0.00 & 0.00 & 0.00 & 0.00 & 0.00 & 0.19 & 1.16 & 0.00 \\
Hanwha & 0.17 & 0.00 & 0.00 & 0.00 & 0.00 & 0.00 & 0.00 & 0.00 & 0.00 & 0.00 & 0.00 & 0.00 \\
KOGAS & 0.00 & 0.00 & 0.00 & 0.00 & 0.00 & 0.00 & 0.00 & 0.00 & 0.00 & 1.00 & 0.00 & 0.00 \\
S-Oil & 0.00 & 0.00 & 0.00 & 0.00 & 0.00 & 0.00 & 0.00 & 0.00 & 0.00 & 0.00 & 1.00 & 0.00 \\
Lotte Shopping & 0.03 & 0.00 & 0.00 & 0.00 & 0.00 & 0.00 & 0.00 & 0.00 & 0.00 & 0.24 & 0.46 & 0.00 \\
\hline
\end{tabular}

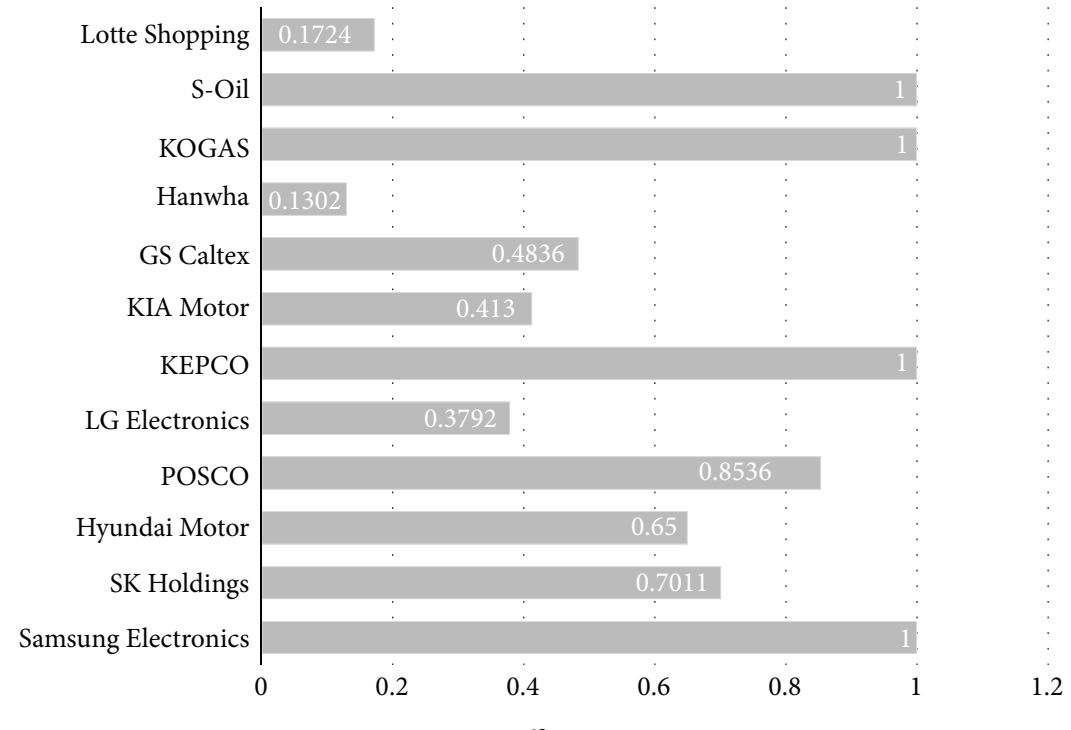

Figure 2: Efficiency score.

TABLE 6: Value of slack variables and reference set.

\begin{tabular}{|c|c|c|c|c|c|}
\hline DMU & $s_{1}^{-}$ & $s_{2}^{-}$ & $s_{3}^{-}$ & $s_{1}^{+}$ & Reference \\
\hline $\begin{array}{l}\text { Samsung } \\
\text { Electronics }\end{array}$ & 0 & 0 & 0 & 0 & {$[1]$} \\
\hline SK Holdings & 0 & 65.47 & 0 & 0 & {$[1,6]$} \\
\hline Hyundai Motor & 6.59 & 0 & 0 & 0 & {$[1,11]$} \\
\hline POSCO & 0 & 178.47 & 0 & 0 & {$[1,6]$} \\
\hline LG Electronics & 2.96 & 0 & 0 & 0 & {$[1,11]$} \\
\hline КEPCO & 0 & 0 & 0 & 0 & [6] \\
\hline KIA Motor & 0 & 0 & 0 & 0 & {$[1,10,11]$} \\
\hline GS Caltex & 0 & 0 & 5.54 & 0 & {$[10,11]$} \\
\hline Hanwha & 2.48 & 2.09 & 0 & 0 & [1] \\
\hline KOGAS & 0 & 0 & 0 & 0 & {$[10]$} \\
\hline S-Oil & 0 & 0 & 0 & 0 & [11] \\
\hline Lotte Shopping & 0 & 0 & 0 & 0 & {$[1,10,11]$} \\
\hline
\end{tabular}

in 2014, considering the appropriate number of DMUs. By reviewing previous studies, the number of goods (the number of purpose businesses), the number of providers (the number of connected companies), and the number of plants and branches, which are the commonly mentioned factors by scholars in the previous studies, are set as input factors. The total sales of year is set as an output factor.

The result findings reveal that the most efficient DMUs are the 4 companies of S-Oil, KOGAS, KEPCO, and Samsung Electronics. The most inefficient companies are Hanwha and Lotte Shopping. Moreover, the companies with higher number of products compared to other companies are Hanwha and Lotte Shopping, and the companies with higher number of related companies compared to other companies are KIA Motor and GS Caltex.

The implications of this study are as follows.

First, this study organizes the factors of supply complexity through literature review and conducts the DEA analysis by 
TABLE 7: Projection point and excess quantity of input.

\begin{tabular}{|c|c|c|c|c|c|c|}
\hline \multirow{3}{*}{$\mathrm{DMU}$} & \multicolumn{6}{|c|}{ Input factor } \\
\hline & \multicolumn{3}{|c|}{ Excess quantity of input } & \multicolumn{3}{|c|}{ Projection point } \\
\hline & $x_{1}$ & $x_{2}$ & $x_{3}$ & $x_{1}$ & $x_{2}$ & $x_{3}$ \\
\hline Samsung Electronics & 0 & 0 & 0 & 29 & 159 & 13 \\
\hline SK Holdings & 6.27 & 128.55 & 7.48 & 14.72 & 82.44 & 17.51 \\
\hline Hyundai Motor & 17.44 & 31.49 & 4.55 & 13.55 & 58.50 & 8.44 \\
\hline POSCO & 1.46 & 217.12 & 0.72 & 8.53 & 46.87 & 4.27 \\
\hline LG Electronics & 23.45 & 62.08 & 10.55 & 9.54 & 37.91 & 6.44 \\
\hline KEPCO & 0 & 0 & 0 & 7 & 76 & 241 \\
\hline KIA Motor & 18.78 & 14.67 & 22.89 & 13.21 & 10.32 & 16.10 \\
\hline GS Caltex & 12.39 & 7.74 & 31.36 & 11.60 & 7.25 & 18.63 \\
\hline Hanwha & 52.06 & 196.92 & 14.78 & 4.93 & 27.07 & 2.21 \\
\hline KOGAS & 0 & 0 & 0 & 6 & 20 & 31 \\
\hline S-Oil & 0 & 0 & 0 & 9 & 3 & 11 \\
\hline Lotte Shopping & 30.62 & 50.48 & 61.24 & 6.37 & 10.51 & 12.75 \\
\hline
\end{tabular}

${ }^{*} x_{1}$ : the number of goods, $x_{2}$ : the number of providers, and $x_{3}$ : the number of plants.

TABLE 8: Result of bootstrap DEA.

\begin{tabular}{|c|c|c|c|c|c|c|c|}
\hline DMU & Score & Bias & Mean & Median & $\mathrm{SD}$ & CI_Lower & CI_Upper \\
\hline GS Caltex & 0.4836 & 0.1118 & 0.3718 & 0.4292 & 0.1443 & -0.0634 & 0.4767 \\
\hline Hanwha & 0.1302 & 0.0399 & 0.0903 & 0.1151 & 0.0498 & -0.0472 & 0.1287 \\
\hline Hyundai Motor & 0.6500 & 0.1090 & 0.5410 & 0.5889 & 0.1474 & 0.0222 & 0.6405 \\
\hline КEPCO & 1.0000 & 0.2027 & 0.7973 & 0.8685 & 0.1967 & 0.2652 & 0.9840 \\
\hline KIA Motor & 0.4130 & 0.1057 & 0.3073 & 0.3600 & 0.1147 & 0.0095 & 0.4069 \\
\hline KOGAS & 1.0000 & 0.2196 & 0.7804 & 0.8290 & 0.1632 & 0.4217 & 0.9847 \\
\hline LG Electronics & 0.3792 & 0.0626 & 0.3166 & 0.3417 & 0.0798 & 0.0390 & 0.3736 \\
\hline Lotte Shopping & 0.1724 & 0.0251 & 0.1473 & 0.1531 & 0.0226 & 0.0834 & 0.1698 \\
\hline POSCO & 0.8536 & 0.2257 & 0.6278 & 0.7581 & 0.2586 & -0.0831 & 0.8434 \\
\hline Samsung Electronics & 1.0000 & 0.4584 & 0.5416 & 0.5489 & 0.4067 & -0.4499 & 0.9857 \\
\hline SK Holdings & 0.7011 & 0.1647 & 0.5364 & 0.6218 & 0.1742 & 0.0932 & 0.6919 \\
\hline S-Oil & 1.0000 & 0.6353 & 0.3647 & 0.5164 & 0.6412 & -1.3279 & 0.9843 \\
\hline
\end{tabular}

utilizing the deduced common factors as input factors. Since the previous studies to analyze supply complexity through DEA do not exist, it is expected that this study will be a foundation for a standard to manage supply complexity efficiently.

Second, this study suggests a standard for supply complexity management of each company by analyzing project point and the excess quantity of input of each DMU. It is expected that this suggestion can allow each company to efficiently manage the supply complexity-related factors such as the number of goods (the number of purpose businesses), the number of providers (the number of connected companies), and the number of plants and branches.

Third, this study selects the objects of benchmarking for companies with inefficient management of supply complexity. It is expected that each company can select DMU with the consideration of their market and industry and then select the object of benchmarking according to reference set.

Finally, this study comparatively compares complexity management efficiency through bootstrap DEA approach.
It is identified that public companies efficiently manage complexity, and service industry relatively manages complexity inefficiently than manufacturing industry.

However, several limitations exist in spite of the advantages of this study above.

This study conducts the analysis targeting domestic companies. Although the objects of this study belong to Fortune Global Top 500, all of the targets are ranked outside 50 except for Samsung Electronics ranked as the 13th. Also, this study considers only 3 input factors among the mentioned factors in the previous studies. It is hoped that future studies can consider a variety of input factors by selecting companies from various nationalities as DMU.

\section{Conflict of Interests}

The authors declare that there is no conflict of interests regarding the publication of this paper. 


\section{Acknowledgment}

This research is supported by the Research Affairs of Seoul National University.

\section{References}

[1] P. Trkman and K. McCormack, "Supply chain risk in turbulent environments-a conceptual model for managing supply chain network risk," International Journal of Production Economics, vol. 119, no. 2, pp. 247-258, 2009.

[2] D. Hur, J. Hartley, and C. K. Hahn, "An exploration of supply chain structure in Korean companies," International Journal of Logistics, vol. 7, no. 2, pp. 151-164, 2004.

[3] G. K. Rand and E. M. Goldratt, "Critical chain," Journal of the Operational Research Society, vol. 49, no. 2, p. 181, 1998.

[4] J. T. Mentzer, W. DeWitt, J. S. Keebler et al., "Defining supply chain management," Journal of Business Logistics, vol. 22, no. 2, pp. 1-25, 2001.

[5] G. C. Stevens, "Integrating the supply chain," International Journal of Physical Distribution \& Materials Management, vol. 19, no. 8, pp. 3-8, 1989.

[6] H. L. Lee and C. Billington, "Managing supply chain inventory: pitfalls and opportunities," Sloan Management Review, vol. 33, no. 3, 1992.

[7] C. H. Fine, Clockspeed: Winning Industry Control in the Age of Temporary Advantage, Basic Books, 1998.

[8] K. C. Tan, R. B. Handfield, and D. R. Krause, "Enhancing the firm's performance through quality and supply base management: an empirical study," International Journal of Production Research, vol. 36, no. 10, pp. 2813-2837, 1998.

[9] D. F. Ross, Competing through Supply Chain Management: Creating Market Winning Strategies Through Supply Chain Partnership, Chapman \& Hall, New York, NY, USA, 1998.

[10] R. B. Handfield and E. L. Nichols, Introduction to Supply Chain Management, Prentice Hall, Upper Saddle River, NJ, USA, 1999.

[11] R. Inger, A. Braithwaite, and M. Christopher, "Creating a manufacturing environment that is in harmony with the marketthe 'how' of supply chain management," Production Planning \& Control: The Management of Operations, vol. 6, no. 3, pp. 246257, 1995.

[12] O. Khan, M. Christopher, and B. Burnes, "The impact of product design on supply chain risk: a case study," International Journal of Physical Distribution and Logistics Management, vol. 38, no. 5, pp. 412-432, 2008.

[13] C. Tang and B. Tomlin, "The power of flexibility for mitigating supply chain risks," International Journal of Production Economics, vol. 116, no. 1, pp. 12-27, 2008.

[14] P. R. Kleindorfer and G. H. Saad, "Managing disruption risks in supply chains," Production and Operations Management, vol. 14, no. 1, pp. 53-68, 2005.

[15] W. Klibi, A. Martel, and A. Guitouni, "The design of robust value-creating supply chain networks: a critical review," European Journal of Operational Research, vol. 203, no. 2, pp. 283293, 2010.

[16] J. K. Deane, C. T. Ragsdale, T. R. Rakes, and L. P. Rees, "Managing supply chain risk and disruption from IT security incidents," Operations Management Research, vol. 2, no. 1-4, pp. 4-12, 2009.

[17] S. C. Ellis, R. M. Henry, and J. Shockley, "Buyer perceptions of supply disruption risk: a behavioral view and empirical assessment," Journal of Operations Management, vol. 28, no. 1, pp. 34-46, 2010.
[18] K. E. Stecke and S. Kumar, "Sources of supply chain disruptions, factors that breed vulnerability, and mitigating strategies," Journal of Marketing Channels, vol. 16, no. 3, pp. 193-226, 2009.

[19] T. Y. Kim and Y. S. Ham, "An ATP system with non-integer time lag for supply chain management," Korean Journal of Business Administration, vol. 22, no. 6, pp. 3673-3691, 2009.

[20] C. C. Bozarth, D. P. Warsing, B. B. Flynn, and E. J. Flynn, "The impact of supply chain complexity on manufacturing plant performance," Journal of Operations Management, vol. 27, no. 1, pp. 78-93, 2009.

[21] R. Ashkenas, "Simplicity-minded management," Harvard Business Review, vol. 85, no. 12, pp. 101-146, 2007.

[22] J. L. Mariotti, The Complexity Crisis: Why Too Many Products, Markets, and Customers Are Crippling Your Company-And What to Do About It, Adams Media, Avon, Mass, USA, 2008.

[23] S. A. Wilson and A. Perumal, Waging War on Complexity Costs: Reshape Your Cost Structure, Free Up Cash Flows and Boost Productivity by Attacking Process, Product and Organizational Complexity, McGraw Hill Professional, 2009.

[24] C. H. Papadimitriou and K. Steiglitz, Combinatorial Optimization: Algorithms and Complexity, Courier Corporation, 1998.

[25] A. Charnes, W. W. Cooper, and E. Rhodes, "Measuring the efficiency of decision making units," European Journal of Operational Research, vol. 2, no. 6, pp. 429-444, 1978.

[26] R. D. Banker, A. Charnes, and W. W. Cooper, "Some models for estimating technical and scale inefficiencies in data envelopment analysis," Management Science, vol. 30, no. 9, pp. 10781092, 1984.

[27] R. C. Nyhan and L. L. Martin, "Comparative performance measurement: a primer on data envelopment analysis," Public Productivity \& Management Review, vol. 22, no. 3, pp. 348-364, 1999.

[28] T. R. Nunamaker, "Using data envelopment analysis to measure the efficiency of non-profit organizations: a critical evaluation," Managerial and Decision Economics, vol. 6, no. 1, pp. 50-58, 1985.

[29] A. Boussofiane, R. G. Dyson, and E. Thanassoulis, "Applied data envelopment analysis," European Journal of Operational Research, vol. 52, no. 1, pp. 1-15, 1991.

[30] V. Arnold, I. Bardhan, W. W. Cooper, and A. Gallegos, "Primal and dual optimality in computer codes using two-stage solution procedures in DEA," in Operations Research: Methods, Models, and Applications, pp. 57-96, Quorum, 1998.

[31] L. Simar and P. W. Wilson, "Sensitivity analysis of efficiency scores: how to bootstrap in nonparametric frontier models," Management Science, vol. 44, no. 1, pp. 49-61, 1998.

[32] P. Hall, "On the bootstrap and confidence intervals," The Annals of Statistics, vol. 14, no. 4, pp. 1431-1452, 1986.

[33] L. Simar and P. W. Wilson, "A general methodology for bootstrapping in non-parametric frontier models," Journal of Applied Statistics, vol. 27, no. 6, pp. 779-802, 2000. 


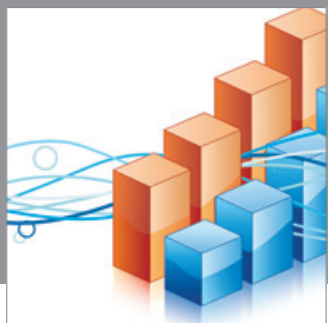

Advances in

Operations Research

mansans

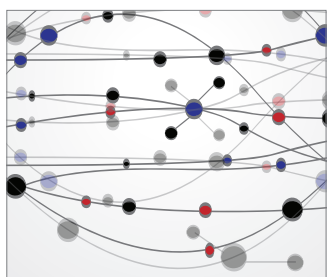

The Scientific World Journal
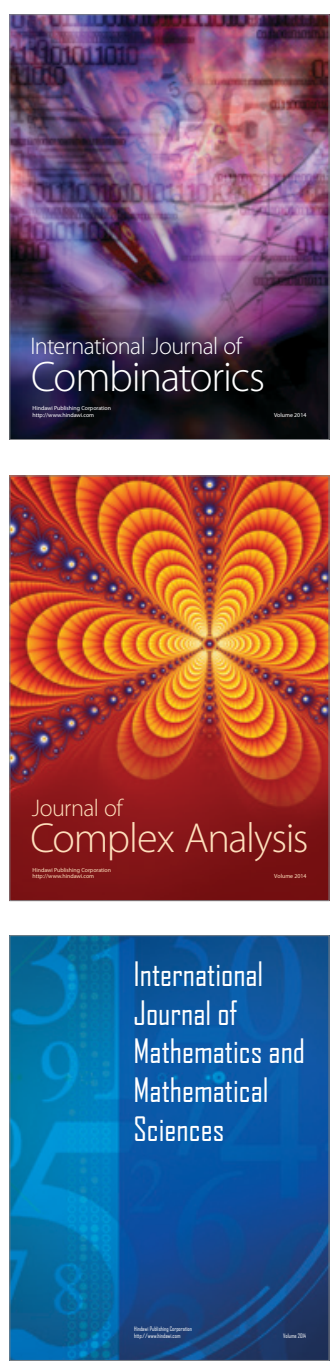
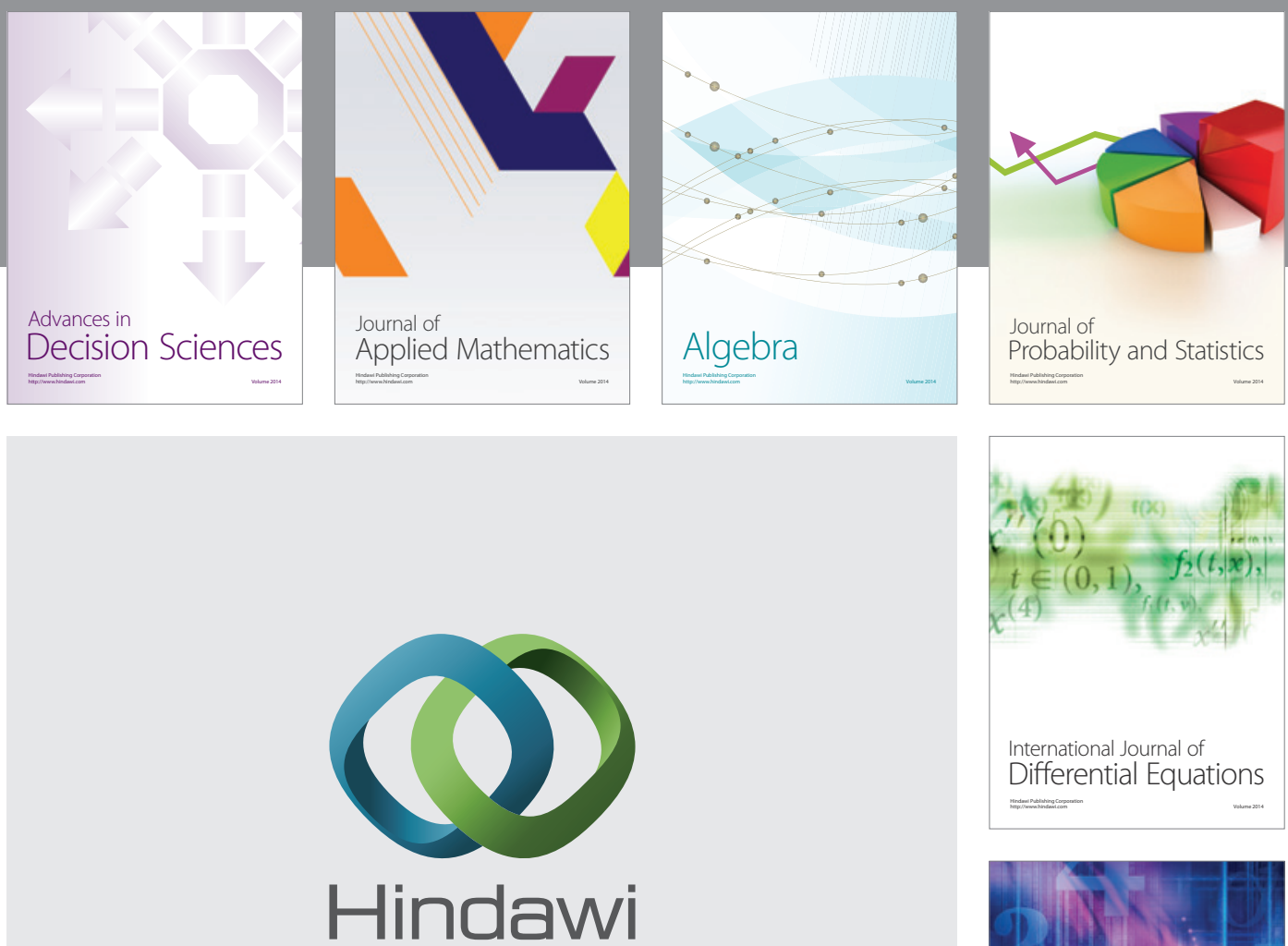

Submit your manuscripts at http://www.hindawi.com
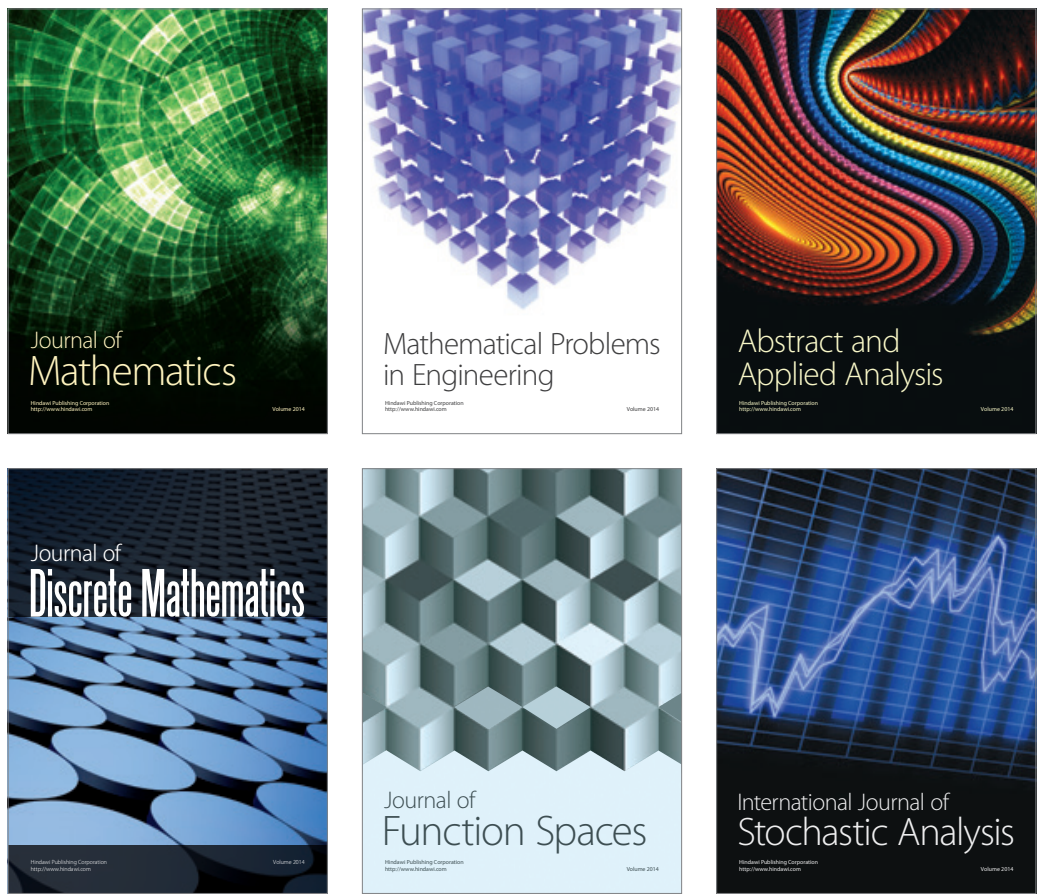

Journal of

Function Spaces

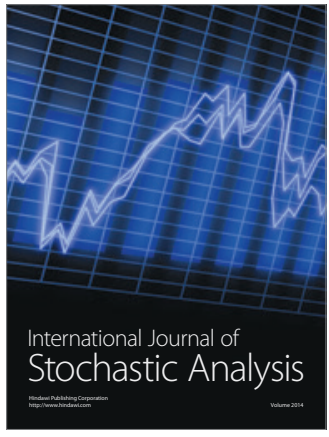

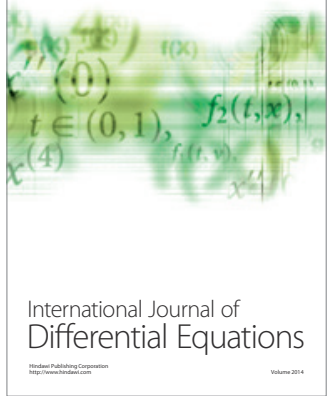
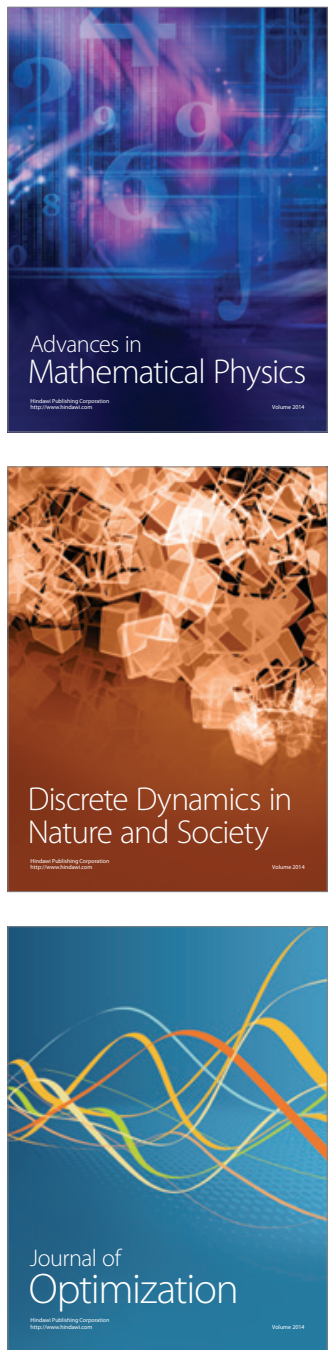